\title{
A Study on the Relationship between Student Engagement and Their Academic Achievements
}

\author{
Iruka Glapaththi ${ }^{1}$, Ravindi Dissanayake ${ }^{1}$, Thilina Welgama ${ }^{1}$, Udara Somachandara ${ }^{1}$, Ranitha Sachinthana \\ Weerarathna ${ }^{1} \&$ Geethma Yahani Pathirana ${ }^{1}$ \\ ${ }^{1}$ Department of Business Management, Sri Lanka Institute of Information Technology, Malabe, Sri Lanka \\ Correspondence: Ranitha Sachinthana Weerarathna, Senior Lecturer, Department of Business Management, Sri \\ Lanka Institute of Information Technology, Malabe, Sri Lanka. Tel: 947-1839-5248. E-mail: ranitha.w@sliit.lk
}

\author{
Received: September 28, $2019 \quad$ Accepted: October 7, $2019 \quad$ Online Published: October 10, 2019 \\ doi:10.5539/ass.v15n11p1 \\ URL: https://doi.org/10.5539/ass.v15n11p1
}

\begin{abstract}
Student engagement has become a dynamically engaging subject within the educational field. Higher student engagement has been a driving force behind extending student accomplishments in academics. This study focuses on student engagement in state (ABC) and non-state (XYZ) universities in Sri Lanka. The purpose of conducting this study is to identify whether a relationship exists between student engagement and academic achievement. The findings of the study will be of significance to the universities as well as the current undergraduates, since it provides an understanding on which measurements of student engagement is to be focused on, in order to achieve superior academic accomplishments. Additionally, the study will be of importance to Sri Lanka as a whole, for despite this subject being investigated in numerous other nations, it was identified that significant consideration was not given to the Sri Lankan context, when investigating the relationship between students' engagement and their scholarly accomplishments. However, there can be unpublished researches in existence. The research was conducted using numerous scientific research tools. A deductive research approach was utilized in the current study. Data collection was based on primary data and a mixed strategy was utilized, as both quantitative and qualitative approaches were taken in collecting data. As per the findings of the study, it was identified that there is a positive relationship between student engagement and their academic achievements.
\end{abstract}

Keywords: academic achievement, campus engagement, class engagement, student engagement

\section{Introduction}

\subsection{Background of the Study}

Significant scholastic accomplishments are the desire of almost everyone, notwithstanding age or gender. Numerous researchers have been interested in the accomplishments of students in school and have conducted studies which verify that poor performance is not just due to the facilities of the schools, but moreover due to the changing levels of student engagement (Foster, 2008). Student engagement is one of the key exploration areas of educational research, especially in educational psychology (Gunuc \& Kuzu, 2015). Student engagement is a multi-faceted construct that can be measured with all the dimensions powerfully interconnected. When considering academic achievements, student engagement is widely recognized as an important concept influencing achievement and learning in higher education (Kahu, 2013). Numerous researchers have identified it as a critical factor in deciding student learning in college and have inquired about it since the 1990's (Casuso-Holgado et al., 2013). When linking student engagement with academic achievement, student participation is identified as behavioral, emotional and cognitive, including academic activities as a key building block in motivation. Many researchers have brought to attention that there is a positive relationship between student engagement and academic achievement (Gunuc, 2014).

By integrating with the global economy, countries that are more effective have reached higher education standards. As a developing country, a large-scale labor market exists in Sri Lanka. Hence it is more important to select qualified people than those who have only school level qualifications. Therefore, the attention given to academic achievements and its relationship with student engagements needs to be questioned. 


\subsection{Statement of Research Problem}

In order to provide a foundation for this study, the researchers have collected data from the Faculty of Business, of ABC University, for the 3rd Year, 2nd semester - 2018 October/ November Final examination results. An analysis of the data, identified that apart from the Management Information Systems (MIS) specialization, all the other specialization areas have a passing rate of less than or almost $50 \%$, out of the undergraduates who sat for the 3rd year 2nd semester final examinations in the said period (Table 1).

Table 1. Faculty of Business of ABC university 3rd Year 2nd Semester (2018 October/November) Final Examination Results

\begin{tabular}{ccc}
\hline Specialization & Number of students who passed the Exam & Passing rate \\
\hline Quality Management & 6 & $50 \%$ \\
Marketing Management & 42 & $36 \%$ \\
Human Capital Management & 29 & $38 \%$ \\
Accounting and Finance & 64 & $53 \%$ \\
\hline
\end{tabular}

Source: Department of Examinations, ABC University

Only 6 undergraduates have faced the examinations in the Quality Management Specialization, while half of them have failed at least one module. The lowest pass rate was shown in the Marketing Management specialization where only 15 out of 42 undergraduates have passed all the modules, which is $36 \%$. Human Capital Management also shows a 38\% pass rate where 29 have faced examinations and only 11 have passed all the modules. Highest number of undergraduates follow the Accounting and Finance degree, where 34 out of 64 have passed, which is 53\% (almost near 50\%) (Table 1). These results could be due to lack of student engagement from undergraduates concerning their studies.

Accordingly, based on the above discussion, the research problem of this study would be, "Is there any relationship between students' engagement and their academic achievements?"

\subsection{Research Objectives}

\subsubsection{Research Questions}

- What is the relationship between students' engagement and academic achievement of business management undergraduates?

- What are the differences in demographic \& socio-economic traits of business management undergraduates?

- What are the differences in student engagement in state and non-state universities?

- How student engagement impacts on the academic achievements?

\subsubsection{Primary Objective}

- To find the relationship between students' engagement and their academic achievement, with special reference to business management undergraduates.

\subsubsection{Secondary Objectives}

- To analyze the demographic and socio-economic traits of the business management undergraduates.

- To analyze the differences of student engagement in state and non-state universities.

- To identify the impact of student engagement on academic achievement.

\subsection{Significance of the Study}

University students: the study investigates the relationship between student engagement and academic achievement. Through this, students who are currently engaged in university studies or those who wish to start university studies can take a decision on the level of engagement in university activities in order to have better academic results. Moreover, this study helps them to identify the causes for low academic achievement and circumvent such engagements.

Universities: ABC University as well as other universities can take decisions and tabulate the means of student engagement so that the students will be able to obtain better grades and better academic achievements. Through that, they can enhance the outcome of their services and boost goodwill too.

Lecturers: they will be able to organize their lecturing techniques and practices so that it will be more effective 
when delivering lectures. Wang et al. (2019) states that efforts to satisfy and improve basic psychological needs at school, would be helpful in improving student behavioral engagement and academic achievement. Hence understanding such factors will be helpful for lecturers to improve the academic achievements of the students.

Researchers: Help to identify the link between the student engagement and academic achievement and will help in understanding to which extent student engagement will affect academic achievement. Since the researchers are still at an undergraduate level, these results will be of assistance in the future when engaging in higher education, to decide how to engage in studies in order to gain better and improved academic achievement.

\section{Literature Review}

\subsection{Student Engagement}

When reviewing past literature, it was identified that in many of the research articles, the researchers have divided student engagement mainly into two components: class engagement and campus/university engagement. Campus engagement has been divided into three components: valuing, participation and sense of belonging (Blimling, 1993; Gunuc \& Kuzu, 2015; Pike \& Kuh, 2005; Terenzini et al., 1996). Class engagement has also been divided into three basics: cognitive, emotional and behavioral engagements.

\subsubsection{Definitions of Student Engagement}

Student engagement in academic work is defined as the student's psychological investment and effort directed toward learning, understanding or grasping the information, aptitudes, or activities that scholastic work aims to advance (Park, 2005). It is also characterized as the students' eagerness, needs, inspiration and craving for success within the learning process (Gunuc \& Kuzu, 2015).

\subsubsection{Types of Student Engagement}

Many authors have classified student engagement in different ways (Gunuc \& Kuzu, 2015; Appleton et al., 2008; Patrick et al., 2007) have identified that there are mainly two types of student engagement: campus engagement and class engagement. The same author divided campus engagement into two further dimensions: valuing and sense of belonging. Class engagement too is divided into three further dimensions: cognitive, emotional and behavioural engagements.

\subsubsection{Campus Engagement}

Campus engagement was given different definitions by different researchers. Willms (2003) has defined campus engagement as the students' sense of belonging, acceptance of the worth of their college and active participation in campus activities. When analysing existing studies it can be noted that, campus engagement has been divided into two main sub categories, namely; sense of belonging and valuing. Appleton et al. (2006) and Gunuc and Kuzu (2015) have identified belonging and valuing as emotional and psychological engagement which includes involvement in university activities and academic teaching.

However, it was found that campus engagement, which comprises of sense of belonging and valuing has a positive and indirect influence on academic achievement and motivation (Goodenow, 1993; Kember et al., 2001).

\subsubsection{Class Engagement}

Class engagement comprises of students' cognitive, emotional and behavioural reactions to in-class and out-of-class activities (Gunuc, 2014). The class engagement component is divided into three main sub categories as discussed above: cognitive, emotional and behavioural engagements. In most of the articles, when analysing the student engagement in class, all most all have divided the class engagement among the discussed sub parts (Appleton et al., 2006).

\subsection{Academic Achievement}

Students' achievements, play a significant part in creating superior quality graduates who will become pioneers in the nation and hence be responsible for the country's financial and social improvement (Ali et al., 2009). A notable body of literature has been conducted on academic achievement. This concept is considered important due to the instructive process between the student, instructor, and institution. Academic achievement is characterized by the student's later grade point average (GPA) (York et al., 2015).

\subsubsection{Definitions of Academic Achievement}

Many past researchers have defined academic achievement in various ways. Kuh et al. (2006) has characterized student success as academic achievement, engagement in instructively measured exercises, fulfillment, procurement of craved information, abilities and competencies, persistence, achievement of instructive results 
and post-college performance. Academic success is found to influence the amount of effort put into activities that are dependent on tasks, and as a result affecting the level of individual achievement (Choi, 2005).

\subsection{Relationship between Student Engagement and Academic Achievement}

The relationship between student engagement and academic achievement has been identified in numerous ways, when considering the studies reviewed.

An article by Kuh (2001b) provides its key findings stating that student engagement has a positive correlation with the grade point average (GPA). Moreover, in the same article it was mentioned that campus engagement has a higher positive correlation with academic achievement than class engagement.

In another article Park (2005), concludes that student engagement has a significantly positive relationship with the academic gains in the mathematics subject. It also states that it has no relationship with the racial or gender changes. Another article by Li et al. (2010), which was conducted to analyse the mathematics performance, has identified that cognitive engagement has a positive influence on the learning of the students. Cognitive engagement is valued by the teaching community and is generally known to encourage learning.

Moreover, in the key findings of an article by Greene et al. (2008), it was found that GPA has a positive link with the time spent on reading and writing while no significant relationship was recorded in the hours employed, single parent, proxy etc.

Nauffal (2012) has stated that faculty interactions and academic achievements have a significant positive correlation. In this study, the researchers have collected data from two faculties: Business and Engineering and have identified that the interactions of the Business students with the faculty activities are weaker than that of the Engineering students. Further it was identified that the academic achievements of the Engineering students are higher compared to Business students.

One of the key findings of the article by Wara et al. (2018), identifies that cognitive engagement has a moderate positive relationship with the academic achievement of the students and that increasing the cognitive engagement results in increases in the academic achievement $(\mathrm{r}=.376, \mathrm{~N}=312, \mathrm{p}<.05)$. In the same study, it was mentioned that students who do not take the assignments seriously have less chance of succeeding in their academics. This being due to the lack of cognitive engagement, meaning that the instructors should have a constant supervision of the students.

An article which was conducted in UK by Appleton et al. (2006) presents its key findings stating that, cognitive and emotional engagement and its measures have an impact on the students' learning and academic achievements. Changes in either of these two engagements has a positive impact on the students' academic achievement. In addition, $\mathrm{Li}$ et al. (2010) has stated that school engagement also has a positive influence on the students' academic achievement and further mentions that school engagement differs from individual to individual, which in turn will result in changes in their academic achievements.

\subsection{Research Gaps}

One of the main research gaps found in a majority of the researches was the sample. In most of the articles, samples collected have been limited to one university/school, which does not provide an accurate representation of the total population. Greene et al. (2008); Handelsman et al. (2005); Gunuc (2014); Pineda-Báez et al. (2014); Sheard et al. (2010); Gunuc and Kuzu (2015); Krause and Coates (2008).

Another common research gap identified was the selection of results of different subjects, to measure academic achievement, which is not a good indicator of academic achievement. For instance, Goodenow (1993) has stated that they have only used English language results to determine the academic achievement, which is unrealistic.

Lack of a qualitative approach has also been identified as a research gap by most of the researchers (Hu \& Kuh, 2002; Pineda-Báez et al., 2014; Krause \& Coates, 2008).

In addition to the above mentioned research gaps, Park (2005); Gunuc and Kuzu (2015); Krause and Coates (2008) and Hausmann et al. (2007) have clearly mentioned that considering undergraduates from all years would convey a better understanding on how the student engagement will differ from year to year.

\subsection{Conceptual Framework}

From the analysis of existing literature, it has been identified that students in higher educational institutes are not performing well due to various reasons. This study assists in taking further steps to investigate a few issues, faced by Sri Lankan universities. The variables to be considered are the changes in class and campus engagements, which is divided up into behavioural, cognitive and emotional engagements. These components 
will affect the academic achievement of the undergraduates which is measured using the GPA.

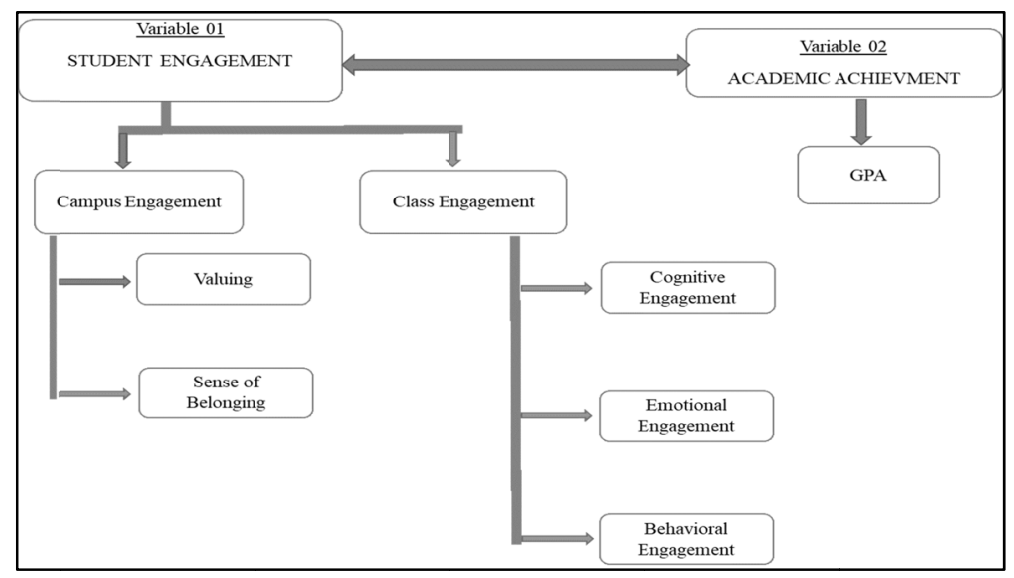

Figure 1. Conceptual Framework

Source: Researchers' Original Construction

\subsection{Hypothesis}

\subsubsection{Main Hypothesis}

$\mathrm{H}_{1}$-There is a relationship between student engagement and academic achievement.

$\mathrm{H}_{0}$ - There is no relationship between student engagement and academic achievement.

\section{Research Methodology}

\subsection{Research Design}

Research design can be expounded as the general outline or the framework of what needs to be done to answer the research questions (Research Methodology, 2019). Through this, it indicates the methods of collecting data and how said data should be analysed in such a way so as to arrive at the conclusion and provide recommendations too, if necessary. There are two perspectives of research designs: qualitative research design and quantitative research design. In the present study, both quantitative \& qualitative research design will be used.

\subsection{Research Approaches}

This study uses a deductive research approach. A deductive research approach starts from a general statement or a hypothesis and then investigates or inspects the chances and prospects of arriving at a conclusion. In deductive research approaches, methods such as testing hypothesis and theories are carried out (Bradford, 2017).

Since this study uses a deductive research approach, the hypotheses are developed based on the literature review. The generalization of this approach will be from general to specific. The data collected is used to assess the hypothesis developed which is related to an existing theory. Ultimately the theory's verification will be done. This study will describe the relationship between the students' engagement and their academic achievement. For instance, it will consider both campus engagement and class engagement to measure student engagement with the collected data. Eventually it will generalize the results by verifying the developed hypotheses.

\subsection{Research Strategies}

A research strategy is a comprehensive plan for carrying out a research study. It traces how the research should be carried out in order to achieve the research objectives (Johannesson \& Perjons, 2014). In this scenario, it aims to find the relationship between student engagement and academic achievement, with special reference to the business management undergraduates. To achieve that, a survey strategy will be used to collect data from the business management undergraduates, from the respective universities. Moreover, the researchers will be using both quantitative and qualitative approaches in arriving at the conclusion, resulting in the use of a questionnaire method under survey strategy. The other research strategy was developed in the form of a face-to-face structured interview method, where approximately ten undergraduates from each university will be selected for the interview sessions, for the qualitative data collection.

\subsection{Data Collection Method}

There are two ways of collecting data: primary and secondary. Primary data refers to data collected from unique 
sources for the specific study (Sekaran \& Bougie, 2010). Therefore, in the present study the data will be collected using the primary method. However, in the present study both quantitative and qualitative data will be used in order to conduct a better investigation of the relationship between student engagement and academic achievement.

\subsubsection{Questionnaire Method}

The present study only consists of primary data which was collected through the structured questionnaire. These questionnaires were prepared according to the measures of dimensions based on the literature review. The questions were taken from the SES (Gunuc \& Kuzu, 2015) and have been changed to suit the Sri Lankan context.

\subsection{Questionnaire Design}

A questionnaire method was adopted as a research strategy as it provides speedy responses. These responses can be analysed in a more scientific manner and data can be gathered from large sample. The questionnaire consists of two parts where part A consists of Demographic questions while the part B contains 5 point Likert scale questions on the student engagement.

\subsection{Methods of Measurements}

\subsubsection{Methods of Measuring Student Engagement}

To measure the dependent variable, the researchers have used 28 statements. The researchers have included questions related to the 2 components of student engagement (class and campus engagement).

\subsubsection{Methods of Measuring Academic Achievement}

In order to measure the independent variable of the present study, the researchers have asked for the GPA (Grade Point Average) of the undergraduates in the demographic section. Moreover, the researchers have also made an optional question requesting to input the index number of the undergraduate, only if they are willing to reveal their identities.

\subsection{Purpose of the Study / Type of Investigation / Study Setting / Unit of Analysis}

The main purpose of the present study is to identify the relationship between student engagement and academic achievement. Sekaran and Bougie (2010) has defined hypothesis testing as a consistently predicted relationship between two or more variables, communicated in the form of a testable explanation. Therefore, based on the purpose of the study it could be taken under hypothesis testing. The present study uses correlation analysis as the type of investigation, as it aims to investigate the relationship between student engagement and academic achievement. As the present study needs to find the relationship between the student engagement and the academic achievement of the business management undergraduates, the researchers will have to develop a theoretical framework, then gather the data and analyse it to obtain more meaningful findings. In this case, researchers' interferences will be minimal. In the present study, the unit of analysis would be individuals, as the questionnaires prepared and the face-to-face interviews will be carried out with individual undergraduates.

\subsection{Population and Sample of the Study}

$\mathrm{ABC}$ and $\mathrm{XYZ}$ Universities consists of a total of 3500 business management undergraduates. When selecting a sample, In the study by Krejcie and Morgan (1970), it is stated that for a total population of 3500, a perfect sample would be 346 and that would represent the entire population. In the present research, the researchers have determined the sample size to be 350 undergraduates from both universities. The researchers have selected the sampling technique as convenience sampling.

\subsection{Data Presentations and Data Analysis Techniques}

The collected data was analysed using IBM Statistical Package for Service Solution (SPSS) version 25. As for the method of data analysis, Correlation analysis was conducted to identify the relationship between the two variables, exploratory factor analysis and frequency distribution was used to analyse the demographics, One Sample T-test and qualitative analysis were used to analyse the differences of student engagement while regression analysis was used to find the impact of student engagement on academic achievement. Furthermore, the hypothesis was tested using the results of the correlation and regression analysis.

\subsection{Reliability of the Measures}

Reliability reflects consistency over time. Reliability is seen as the degree to which a test is free from estimation mistakes, since the more estimation blunders happen the less tried and true the test will be (Fraenkel \& Wallen, 2003; Schumacher \& Mcmillan, 2006; Moss, 1994). IBM SPSS Statistics Software was used to check the 
reliability of the measures and the consistency of the measurements using Cronbach's Alpha. Before conducting the survey, a pilot study was implemented to check the reliability using 20 responses, where the gathered data were checked for reliability before conducting the main survey.

\subsection{Limitations of the Study}

Primarily, since the study is only limited to two universities (including one state and one non- state university) to identify the relationship between the student engagement and the academic achievement, it would not be enough to give a conclusion on all the university students' relationship with student engagement and the academic achievement. Moreover, the researchers have focused only on the business management undergraduates, which will be not be the best indicator to represent the entire university system. Also, the sampling technique acts as an impediment, since the analysts will be utilizing convenience sampling to gather the data, hence it might lead to biasness and eventually the results might not be satisfactorily sufficient to grant a wider representation of the overall population due to the lack of distribution.

\section{Data Analysis and Discussion}

\subsection{Introduction}

The researchers have conveyed 344 surveys from the selected sample. 325 surveys were received in total, from which 5 were rejected due to being deficient while 2 were discarded due to having extreme values. Finally, 318 surveys were utilized for the analysis which sums as $92 \%$

\subsection{Reliability Testing and Validity Testing}

The result from the Cronbach's Alpha value ranges from 0.8-0.9, which implies that the data set contains a high level of consistency. On the other hand, validity refers to the degree to which data collection procedures accurately measure what they were expecting to measure (Saunders et al., 2009). Both reliability and validity checks ought to be carried out to confirm that the dataset is solid and substantial, thereby allowing the researchers to proceed with the analysis.

Table 2. Cronbach's Alpha for the dimensions of the student engagement in main survey

\begin{tabular}{ccc}
\hline Dimensions & No of Items & Cronbach's Alpha \\
\hline Value & 5 & 0.765 \\
Sense of Belonging & 6 & 0.87 \\
Campus Engagement & 11 & 0.884 \\
Cognitive Engagement & 6 & 0.832 \\
Behavioral Engagement & 5 & 0.814 \\
Emotional Engagement & 6 & 0.817 \\
Class Engagement & 17 & 0.914 \\
Student Engagement & 2 & 0.942 \\
\hline
\end{tabular}

As seen in Table 2, student engagement has a high Cronbach's alpha of 0.942 which suggested that the dataset is profoundly solid. Class engagement features a higher reliability of 0.914 when compared with campus engagement. The least consistency was found in the component: value. However, when concluding the results of the Cronbach's alpha of the data set, it could be said that all the components within the data set are reliable.

Table 3. Case processing summary (validity test)

\begin{tabular}{cccc}
\hline & & $\mathrm{N}$ & $\%$ \\
\hline \multirow{3}{*}{ Cases } & Valid & 318 & 100.0 \\
& Excluded & 0 & .0 \\
& Total & 318 & 100.0 \\
\hline
\end{tabular}

a. List wise deletion based on all variables in the procedure.

Table 3 outlines the validity of the data set. As seen, the validity appeared $100 \%$ which implied that the data set is valid enough to go ahead with the data analysis.

However, when concluding the reliability and validity assessment, it can be said that since both the test results came up satisfactory, the data examination could be carried out.

\subsection{Analysis of the Demographic and Socio-Economic Traits of the Business Management Undergraduates.}

\subsubsection{Frequency Distribution of the Demographic Variables}

The sample was presented with eight demographic and socio-economic questions relating to the undergraduates' 
backgrounds and current situations. These data were analysed using frequency distribution tables in order to get a clear understanding about the distributions between the two universities.

Table 4. Frequency distributions of demographic \& socio-economic variables

\begin{tabular}{|c|c|c|c|}
\hline \multirow[t]{2}{*}{ Demographics } & & \multicolumn{2}{|c|}{ Universities } \\
\hline & & $\mathrm{ABC}$ & $\mathrm{XYZ}$ \\
\hline \multirow[t]{2}{*}{ Gender } & Male & $31.46 \%$ & $44.29 \%$ \\
\hline & Female & $68.54 \%$ & $55.71 \%$ \\
\hline \multirow[t]{4}{*}{ Year at the University } & 1st Year & $24.72 \%$ & $5 \%$ \\
\hline & 2nd Year & $21.91 \%$ & $56.43 \%$ \\
\hline & 3rd Year & $26.97 \%$ & $28.57 \%$ \\
\hline & 4th Year & $26.40 \%$ & $10 \%$ \\
\hline \multirow[t]{4}{*}{ Secondary School } & Government & $75.84 \%$ & $78.57 \%$ \\
\hline & Private & $7.87 \%$ & $8.57 \%$ \\
\hline & Semi Government & $10.67 \%$ & $7.14 \%$ \\
\hline & International & $5.62 \%$ & $5.71 \%$ \\
\hline \multirow[t]{3}{*}{ Medium Studied } & Sinhala & $73.03 \%$ & $80 \%$ \\
\hline & English & $24.72 \%$ & $14.29 \%$ \\
\hline & Tamil & $4.49 \%$ & $2.86 \%$ \\
\hline \multirow[t]{2}{*}{ Parents' Education } & Graduate & $35.39 \%$ & $26.43 \%$ \\
\hline & Not Graduated & $64.61 \%$ & $57.87 \%$ \\
\hline \multirow[t]{4}{*}{ Place of stay } & Home & $56.74 \%$ & $64.43 \%$ \\
\hline & Relative's Place & $7.30 \%$ & $11.42 \%$ \\
\hline & Outside Boarding School & $33.71 \%$ & $35.71 \%$ \\
\hline & Campus Hostel & $2.23 \%$ & $6.43 \%$ \\
\hline
\end{tabular}

Source: Author's Construction Based on results generated from SPSS

Table 4 shows how the sample demographics are categorized. Gender: as seen, portrays that a higher number of females compared to males have taken part in the survey, from both the universities. The participation of male respondents from $\mathrm{ABC}$ university is $31.46 \%$ while female is $68.54 \%$ which is more than double. However, in $\mathrm{XYZ}$ University, in spite of the fact that female representation is higher, there has been a relatively equal distribution. ABC University has encompassed a more distributed number of respondents throughout the years.

When considering XYZ University, the most significant number of respondents can be seen from the 2nd year, which sums up to $56.43 \%$, whereas the least number of respondents are from the 1 st year, whose summation is $5 \%$.

Secondary school data and the medium of study were inquired from the respondents, in order to identify the educational background of the participants. As seen in Table 4 both universities' most noteworthy representation has come from government schools.

ABC University had more students coming from semi government schools than XYZ University. It could be concluded that in both of the universities most noteworthy number of respondents have done their secondary tutoring in Sinhala medium. Moreover, $\mathrm{ABC}$ has the most significant number of representatives from the other mediums than XYZ University.

Place of stay incorporated the current residential locations of the undergraduates. Most respondents have come from home: $\mathrm{ABC}-56.74 \%$ and $\mathrm{XYZ}-64.43 \%$. Number of respondents from outside boarding schools were identified to be; $\mathrm{ABC}-33.71 \%$ and $\mathrm{XYZ}-35.71 \%$. A minimal number of respondents remained at the campus lodgings in both the universities. These rates could be basically influenced by the comfort levels of the students.

Parents' education levels moreover gives an insight into the educational foundation of the students. Higher percentage of parents have not been graduated in either of the colleges. Whereas in ABC - 35.39\% and XYZ $26.43 \%$ of the respondents' parents' have graduated.

\subsection{Exploratory Factor Analysis of Demographic Variables}

Exploratory factor Analysis (EFA) is a measurable technique that is utilized to compress information into a smaller set of underlying factors and to investigate the basic hypothetical structure of the phenomena, by clustering the factors into distinctive components (Yong \& Pearce, 2013). Prior to conducting EFA, for the 
purpose of testing whether the sample size was satisfactory to run EFA, the Kaiser-Meyer-Olkin (KMO) \& Bartlett's test were conducted. The KMO test determines whether or not sufficient items are anticipated by each factor where it would be classified as insufficient if $\mathrm{KMO}<0.50$. The present study has a KMO statistic of 0.501 . The Bartlett test is said to be critical, since it implies that the factors are correlated, and are exceedingly sufficient to supply a sensible premise for EFA within the study where the current study has a $p$ value of $p<0.05$ (Table 5).

Table 5. KMO \& Bartlett's test for EFA

\begin{tabular}{lcc}
\hline Kaiser-Meyer-Olkin Measure of Sampling Adequacy. & .501 \\
\hline & Approx. Chi-Square & 68.000 \\
Bartlett's Test of Sphericity & Df & 28 \\
& Sig. & .000 \\
\hline
\end{tabular}

In order to decide the factor structure of the scale, Principal Component Analysis was utilized as the extraction strategy, and Varimax, an orthogonal rotation strategy with Kaizer Normalization, was conducted as well. In EFA, when choosing the number of components, explanatory methods such as scree plot and contributions to variance were utilized. The Total Variance Explained table shows how the fluctuation was divided among the eight demographic factors the researchers took into consideration. When the eigenvalue is less than 1.0 the figure clarifies less data than a single item would have clarified.

Table 6. Total variance explained

\begin{tabular}{|c|c|c|c|c|c|c|c|c|c|}
\hline \multirow{2}{*}{$\begin{array}{c}\text { Compone } \\
\mathrm{nt}\end{array}$} & \multicolumn{3}{|c|}{ Initial Eigenvalues } & \multicolumn{3}{|c|}{$\begin{array}{c}\text { Extraction Sums of Squared } \\
\text { Loadings }\end{array}$} & \multicolumn{3}{|c|}{$\begin{array}{c}\text { Rotation Sums of Squared } \\
\text { Loadings }\end{array}$} \\
\hline & Total & $\begin{array}{c}\text { \%of } \\
\text { Variance }\end{array}$ & $\begin{array}{c}\text { Cumulative } \\
\%\end{array}$ & Total & $\begin{array}{c}\text { \%of } \\
\text { Variance }\end{array}$ & $\begin{array}{c}\text { Cumulative } \\
\%\end{array}$ & Total & $\begin{array}{c}\text { \%of } \\
\text { Variance }\end{array}$ & $\begin{array}{c}\text { Cumulative } \\
\%\end{array}$ \\
\hline 1 & 1.412 & 17.655 & 17.655 & 1.412 & 17.655 & 17.655 & 1.284 & 16.054 & 16.054 \\
\hline 2 & 1.232 & 15.395 & 33.049 & 1.232 & 15.395 & 33.049 & 1.202 & 15.019 & 31.073 \\
\hline 3 & 1.104 & 13.801 & 46.850 & 1.104 & 13.801 & 46.850 & 1.155 & 14.439 & 45.512 \\
\hline 4 & 1.031 & 12.883 & 59.733 & 1.031 & 12.883 & 59.733 & 1.138 & 14.221 & 59.733 \\
\hline 5 & .960 & 11.995 & 71.728 & & & & & & \\
\hline 6 & .829 & 10.369 & 82.097 & & & & & & \\
\hline 7 & .759 & 9.493 & 91.590 & & & & & & \\
\hline 8 & .673 & 8.410 & 100.000 & & & & & & \\
\hline
\end{tabular}

Extraction Method: Principal Component Analysis.

Within the present study there were four components with Initial Eigenvalues more than 1.0 as per Table 6 , where the first component has clarified $17.65 \%$ of the total variance whereas second, third and fourth have clarified $15.39 \%, 13.80 \% \& 12.88 \%$ respectively of the eight socioeconomic components. Taking these four variables as a cutting point, the researchers have chosen to move along with a four-component arrangement for present study. When considering the rotation sums of the square loading, it was obvious that more than half of the variations were accounted for by the four variables where cumulative of $59.73 \%$ (nearly $60 \%$ ) was present.

Table 7. Rotated component matrix

\begin{tabular}{ccccc}
\hline & & Component & \\
& 1 & 2 & & \\
\hline Place of Stay & .702 & & \\
Gender & -.686 & .647 & -.312 & -.493 \\
Have your Parents Graduated & & .624 & .733 \\
University & .408 & -.592 & .711 & .891 \\
Year at the University & & & \\
Secondary School & & & \\
Medium Studied & & & \\
Area of specializations & & & \\
\hline
\end{tabular}

Extraction Method: Principal Component Analysis.

Rotation Method: Varimax with Kaiser Normalization. 
For Table 7 Table 6, loadings less than 0.30 were excluded from the output, where place of stay \& gender were stacked on Component 1, Parents' educational status, undergraduate's university and the year at the university were loaded on Component 2, secondary school and medium considered in secondary school were loaded on Component 3 and area of specialization was loaded exclusively on Component 4 . The area of specialization was anticipated by its own component, as it did not have strong loadings on any of the other factors meaning the area of specialization were weakly related with other factors having its correlation spread between -0.152 to +0.032 .

The Component-1 explains how gender considers the distance to the university, security and comfortability differently when choosing a place to stay. The Component- 2 explained about the university status where undergraduates' choice of entering into a state or non-state university maybe related to their parents' educational status. Component-3 explains about the educational background of the students, where the medium they have studied may have been based on their secondary school.

\subsection{Analysis of the Differences of Students Engagement in State \& Non-State Universities}

\subsubsection{Independent Sample T-test}

The Independent sample T-test was essentially done to compare the means of two independent groups, in order to identify if there is statistical evidence that the population means are significantly different. The Group statistics were produced utilizing $\mathrm{ABC}=178$ (mean=3.65, $\mathrm{SD}=0.561$ ) and $\mathrm{XYZ}=140$ (mean=36, $\mathrm{SD}=0.536$ ), largest group being $\mathrm{ABC}$ university (Table 8 )

Table 8. Independent sample t-test

\begin{tabular}{|c|c|c|c|c|c|c|c|c|}
\hline & & \multicolumn{2}{|c|}{$\begin{array}{c}\text { Levene's Test } \\
\text { for Equality of } \\
\text { Variances } \\
\end{array}$} & \multicolumn{5}{|c|}{ t-test for Equality of Means } \\
\hline & & $\mathrm{F}$ & Sig. & $\mathrm{t}$ & Df & $\begin{array}{c}\text { Sig. } \\
\text { (2-tailed) }\end{array}$ & $\begin{array}{c}\text { Mean } \\
\text { Difference }\end{array}$ & $\begin{array}{l}\text { Std. Error } \\
\text { Difference }\end{array}$ \\
\hline Student & Equal variances assumed & .380 & .538 & .805 & 316 & .020 & .050 & .062 \\
\hline Engagement & Equal variances not assumed & & & .809 & 304.217 & .034 & .050 & .062 \\
\hline
\end{tabular}

As $p=0.538$ where $p<0.05$ which implied that the changeability of the two variables are the same. In addition, it can be seen that the $p=0.020$ which concludes that there's a statistically significant distinction between the student engagements in the two universities.

\subsubsection{Qualitative Analysis}

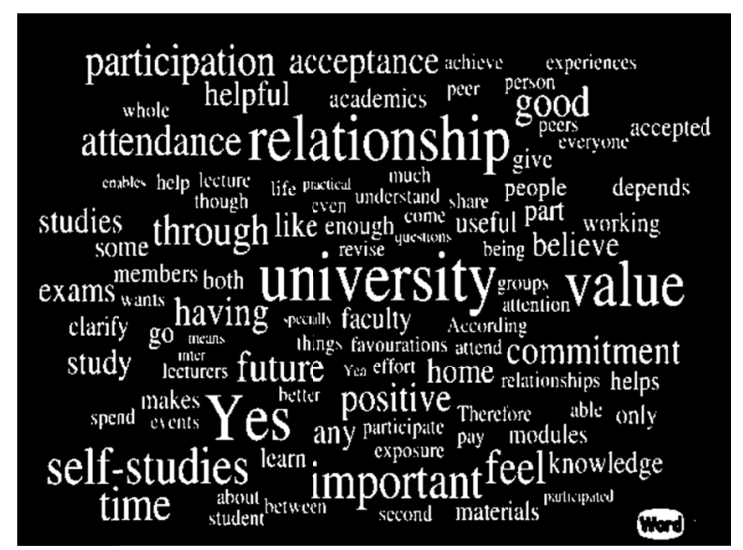

Figure 2. Word Cloud Results of ABC

Source: Word-It-Out Software

According to the results for $\mathrm{ABC}$ University, it is seen that the words value, university, relationship, self-studies, participation and attendance have been highlighted. The word 'value' which comes under campus engagement, is highlighted since the word has been mentioned frequently. An example from the survey is below:

"Having a degree and the experience I got through the studying process has added value to my life which will be helpful in the future. Therefore, I value the university"

"It is important. Because there are some subjects, I don't understand even though I attend the lectures but still I 
attend because when I revise them for the exams, though I didn't understand at the lecture time it makes it easier to revise. Our lecturers encourage participation in classes as they give us time to clarify the questions."

The above phrase states that students from $\mathrm{ABC}$ believe in attending and participating in lectures on a regular basis. Therefore, it can be presumed that behavioural engagement of $\mathrm{ABC}$ is high.

Emotional engagement, represents the students' attitudes, interests, and connections with lecturers in the university, other staff and students.

"I have positive relationships with both peers and my lecturers and I believe it is important to have good relationships with them as with lecturers, which would mean that we can go to them whenever we have a problem regarding subject matters and with the peer groups means that it helps to share the knowledge which would be useful for exams."

This kind of responses show that the students of $A B C$ believe in having positive relationships with lecturers, staff and other students which will help in their studies, with sharing knowledge and experiences etc.

When investigating the answers given, it can be seen that even students who are employed believe that they give their maximum effort to their studies, even though it might be at a lesser extent compared to full time students. This provides an explanation for the highlighting of the word "self-studies" which means cognitive engagement.

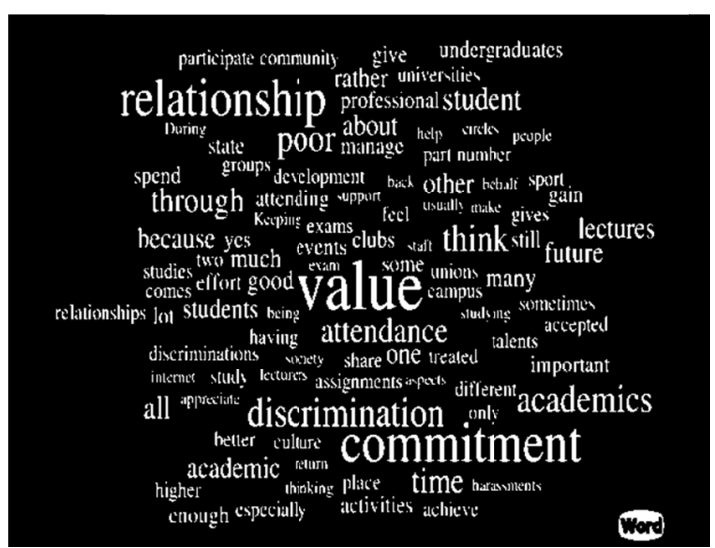

Figure 3. Word Cloud Results of XYZ

Source: Word-It-Out Software

The word 'value' has also been highlighted. It can be safely concluded, based on the responses, that the undergraduates value their university. A response from a participant was as follows:

"I value my university. As an undergraduate in a government university we gain a higher recognition in society for our academic achievements, because there is a general view in Sri Lankan community where state undergraduates are treated with priory based on the degree certificate."

As seen discrimination was also highlighted. Through the responses it pointed out that even though there was acceptance up to a certain level, almost every student did not feel accepted and part of the university due to the factors like discrimination and favoritism. The following response proves this:

"We are accepted as a part of university, where we are treated as one whenever there are events and occasions. Behind all these, there are still some discriminations. For an example this issue is highlighted in first year, where people are treated low for their gender, race or based on their hometowns."

The word 'commitment' comes as a result of cognitive engagement. It reveals that cognitive engagement of the students existed, yet some believed that enough time and effort is not given, since time is hard to manage.

"I believe attendance to classes are not important because at the end commitment will matter and the results will be based on the time spent on learning"

It is seen that the word 'relationship' is highlighted which is a result of emotional engagement. A survey response is given below.

"A good relationship with the lecturers is important as it helps us to get clarifications when we come across an academic related problem and peer relationship is also important as we can share knowledge"

When concluding, it is seen that the two universities have different student engagement levels in them, and it was also identified that $\mathrm{ABC}$ students have more student engagement than that of XYZ students 


\subsection{Identify of the Impact of Student Engagement on Academic Achievement}

The analysts have utilized regression analysis to investigate the impact of student engagement on academic achievement. Simple linear regression was used to measure how the dependent variable could be impacted by the independent variables.

Table 9. Regression Table

\begin{tabular}{cccccc}
\hline Dimensions & $\mathrm{r}$ & $\mathrm{r}^{2}$ & $\begin{array}{c}\text { Sig. } \\
\text { (2-Tailed) }\end{array}$ & Unstandardized coefficient (Beta) & Standardized coefficient (Beta) \\
\hline Value & 0.840 & 0.775 & 0.000 & 0.479 & 0.88 \\
Sense of Belonging & 0.825 & 0.68 & 0.000 & 0.647 & 0.825 \\
Campus Engagement & 0.903 & 0.816 & 0.000 & 0.611 & 0.903 \\
Cognitive Engagement & 0.856 & 0.733 & 0.000 & 0.598 & 0.856 \\
Behavioral Engagement & 0.452 & 0.205 & 0.000 & 0.335 & 0.452 \\
Emotional Engagement & 0.519 & 0.269 & 0.000 & 0.283 & 0.519 \\
Class Engagement & 0.799 & 0.639 & 0.000 & 0.687 & 0.799 \\
Student Engagement & 0.912 & 0.832 & 0.000 & 0.735 & 0.912 \\
\hline
\end{tabular}

After examining the outcome of the Campus Engagement it was seen that the results of 'Value' $(\mathrm{r}=0.840$, $\left.\mathrm{r}^{2}=77.5 \%, \mathrm{~B}=0.479, b=0.88 \& \mathrm{p}<0.05\right)$ is more compelling for the GPA than that of 'Sense of Belonging' $\left(\mathrm{r}=0.825, \mathrm{r}^{2}=68 \%, \mathrm{~B}=0.647, b=0.825 \& \mathrm{p}<0.05\right)$, however both dimensions are in a statistically significant relationship with GPA. With the $\mathrm{r}=0.903, \mathrm{r}^{2}=81.6 \%, \mathrm{~B}=0.611 \& \mathrm{p}=0.000$, Campus engagement, as a whole would indicate high impact on GPA

On the other hand the results of Class Engagement shows 'Cognitive Engagement' $\left(r=0.856, r^{2}=773.3 \%\right.$, $\mathrm{B}=0.598, b=0.856 \& \mathrm{p}<0.05)$ as being the highest influencer on GPA, 'Behavioural Engagement' $(\mathrm{r}=0.452$, $\left.\mathrm{r}^{2}=20.5 \%, \mathrm{~B}=0.335, b=0.452 \& \mathrm{p}<0.05\right)$ showed the lowest impact on GPA while 'Emotional Engagement' $\left(\mathrm{r}=0.512, \mathrm{r}^{2}=26.9 \%, \mathrm{~B}=0.283, b=0.519 \& \mathrm{p}<0.05\right)$ too has a statistically significant relationship with GPA as the rest of the dimensions. When factors are included Class Engagement could be explained by $r=0.799, r^{2}=63.9 \%$, $\mathrm{B}=0.687 \& \mathrm{p}=0.000$. When giving a conclusion on student engagement, the $\mathrm{r}$ of 0.912 suggests that the relationship between student engagement and the GPA are highly correlated (Table 9).

\subsection{The Relationship between Students' Engagement and Their Academic Achievement}

Correlation Coefficient was used to achieve the main objective of the study, which is to find the relationship between students' engagement and their academic achievement. Pearson's Product Moment Correlation Coefficient (PMCC) was utilized to assess the strength of the relationships.

Table 10. Correlation table

\begin{tabular}{cccc}
\hline Dimensions & No of items & Correlation & Sig. 2 tailed \\
\hline Campus Engagement & 318 & 0.903 & 0.000 \\
Valuing & 318 & 0.840 & 0.000 \\
Sense of Belonging & 318 & 0.825 & 0.000 \\
Class Engagement & 318 & 0.799 & 0.000 \\
Cognitive Engagement & 318 & 0.856 & 0.000 \\
Emotional Engagement & 318 & 0.519 & 0.000 \\
Behavioural Engagement & 318 & 0.452 & 0.000 \\
Student Engagement & 318 & 0.912 & 0.000 \\
\hline
\end{tabular}

In order to measure the relationship between GPA and campus engagement, the mean average of its two dimensions; valuing and the sense of belonging were tested separately using PMCC. The correlation of the 'valuing' dimension ( $\mathrm{r}=0.840, \mathrm{p}=0.000)$ and 'sense of belonging' $(\mathrm{r}=0.825, \mathrm{p}=0.000)$ had statistically significant moderate to strong positive relationships with GPA. The undergraduates with higher GPA have strongly agreed to the fact that the university gives them great value while providing them with a feeling of being accepted in the university community, feeling of being secure and opportunities to spend time happily in the campus environment. Subsequently, these results have led to a statistically significant strong positive relationship between Campus Engagement and the GPA with an $r$ value of 0.903 (Table 10). 
The relationship between GPA and class engagement was measured using the mean average of its three dimensions; cognitive engagement, emotional engagement and behavioural engagement, which were tested separately using PMCC. Cognitive $(r=0.856, p=0.000)$, behavioural $(r=0.452, p=0.000)$ and emotional $(r=0.825$, $\mathrm{p}=0.000$ ) proved to being in statistically significant positive relationships. These results lead to a statistically significant moderate positive relationship between classroom Engagement and the GPA ( $r=0.799)$. Though this could prove that the undergraduates could achieve higher grades with higher classroom engagement, a larger portion of this relationship is based on the undergraduate's own investment in academics, which is their cognitive engagement, and not the relationship among groups or participating in classroom activities. The undergraduates with higher GPA have mostly agreed and strongly agreed to the fact that that their investment on learning matters helps to achieve higher grades and the fact that good relationships affect their studies in a good way. Though there is a positive relationship with the behavioural dimension, it was identified that the undergraduates were not too concerned on the behavioural attributes with regards to the academic achievements (Table 10).

Subsequently, mean average of the campus and class engagement were examined, in order to obtain an overall result as an individual variable, which gave an $\mathrm{r}=0.912$ with a $\mathrm{p}=0.000$, to demonstrate statistically significant strong positive relationships with Academic Achievement. Be that as it may, cognitive engagement is very vital for the student's academic achievement, because the undergraduates with higher grades have concurred on the reality that their own investment in the studies would eventually lead to accomplishments in studies, while participation or the relationships with the groups within the classroom would not to a great extent relate to their academics. At the same time, undergraduates with higher grades were convinced of the fact that they are in a valuable campus environment where they are a part of the university framework.

\subsection{Hypothesis Testing}

The Hypothesis were tested after conducting the correlation and regression analysis. According to the results obtained for the study, the Null hypothesis was rejected as $\mathrm{p}<0.05$, and the alternative hypothesis was accepted, which indicated that there is a relationship between student engagement and their academic achievement.

\subsection{Discussion}

When relating the data analysis to past literary works, it can be observed that the analysts have conducted the survey in just one university. When comparing the results of past studies with the current study, the authors identified a few similarities with the results as well as a few contradictions. The research conducted by Gunuc (2014) has identified that there is a statistically significant positive relationship between student engagement and academic achievement. Additionally, the same author has further identified that the cognitive dimension of student engagement has a higher positive relationship with student engagement than the rest of the dimensions. A research which was conducted by Kuh (2001a), has concluded that student engagement has a positive correlation with academic achievement and further, campus engagement has had a higher relationship with academic achievement than class engagement. In the present study, it was discovered that student engagement contains a significantly higher relationship with academic achievement $(\mathrm{r}=0.912)$ and here too the campus engagement's correlation was higher than the class engagement: $r=0.903$. One of the foremost commonly found results from numerous researches were the correlation with cognitive engagement.

A majority of the researchers have discovered that cognitive engagement has a significant relationship with scholarly accomplishments than any other components. In the present study, the most significant relationship was found within campus and class engagement and cognitive engagement (Greene et al., 2008). A research which was conducted by Nauffal (2012) has come to the conclusion that emotional engagement encompasses a significantly high relationship with scholastic accomplishment. However, this result came to act as contradiction with the present research. However, as per the present study, a strong relationship was not found, instead a moderate significant relationship was identified.

\section{Conclusion and Recommendations}

\subsection{Conclusion}

Pearson's' Product Moment Correlation is used to analyse the core objective: the relationship between student engagement and the academic achievements. The outcome of the study demonstrates that there is a statistically significant, strong positive relationship between the two variables. Further, the campus engagement component has a better relationship than the class engagement component and cognitive engagement has the strongest relationship with the scholarly accomplishment whereas behavioural engagement has the least strong relationship. 
The first sub objective of the study is to analyse the demographic components of the business management undergraduates using frequency distributions and exploratory factor analysis. The results were taken independently for the two universities, and it was identified that in both the universities female representation was higher than that of the males and the majority of the participants have studied in government schools, in Sinhala medium. Exploratory Factor Analysis assembles eight demographic variables into four components based on the correlations (Component - 1 gender and the place to stay, Component - 2 the university status, Component -3 educational background of the students and Component -4 area of specialization).

The second objective of the current study was to analyse the contrast between the student engagement levels of the two universities. Here, it utilizes both quantitative and qualitative investigations. Independent sample T-test results, $(\mathrm{p}=0.02)$ proves that there's a statistically significant distinction between the student engagement level of the two universities. Through the qualitative analysis it was identified that state university students value a more emotional engagement whereas non state university students give more significance to cognitive engagement and the valuing aspect, where they tend to have higher student engagement than the state university undergraduates.

The third specific objective was to discover the impact of student engagement on academic achievement. As per the simple linear regression analysis, it was proven that scholarly accomplishments are in fact influenced and impacted by the level of student engagement, cognitive engagement being the highest influencer.

In most of the past studies, the dependent variable being the academic achievement and the independent variable which is the student engagement, is divided into two main components: class engagement (cognitive engagement, emotional engagement and behavioural engagement) and campus engagement (valuing and sense of belonging) (Gunuc, 2014). After analysing the past literature, the conceptual framework was created utilizing these above mentioned independent and dependent variables. The results generated in the analysis are more similar to the past studies conducted. It is established that there is a statistically significant, strong positive relationship between student engagement and academic achievement, while student engagement has a significant and solid impact on the academic achievements of the undergraduates.

\subsection{Recommendations for Future Research}

The present study is aimed at finding the relationship between student engagement and the academic achievement of the business management undergraduates. When considering the limitations of the study, one of the main limitations found was that this study was only conducted focusing on business management undergraduates. As the results from the present study show a measurable significant relationship between student engagement and scholastic accomplishment, this would be imperative to other faculty undergraduates as well. Therefore, when conducting future studies the researchers could conduct the research covering other faculties as well.

In addition, the sample is 350 undergraduates from two universities only. Hence, the results would not give an adequate representation of all the undergraduates in the country. Therefore, when conducting future research regarding the topic, it is suggested that the research be conducted using a larger sample size from a number of higher educational institutes in order to allow a better representation of the population.

Moreover, in this present study, the analysts have utilized convenience sampling, which might have knowingly or unknowingly driven to biasness. Hence, when conducting future studies, it is suggested to utilize simple random sampling to dodge biasness and increase the distribution.

\section{References}

Ali, N., Jusoff, K., Ali, S., Mokhtar, N., \& Salamat, A. S. A. (2009). The factors influencing students' performance at Universiti Teknologi MARA Kedah, Malaysia. Management Science Engineering, 3(4), 81. https://doi.org/10.3968/j.mse.1913035X20090304.010

Appleton, J., Christenson, S. L., Kim, D., \& Reschly, A. L. (2006). Measuring cognitive and psychological engagement: Validation of the Student Engagement Instrument. Journal of School Psychology, 44(5), 427-445. https://doi.org/10.1016/j.jsp.2006.04.002

Appleton, J. J., Christenson, S. L., \& Furlong, M. J. (2008). Student engagement with school: Critical conceptual and methodological issues of the construct. Psychology in the Schools, 45(5), 369-386. https://doi.org/10.1002/pits.20303

Blimling, G. S. (1993). The influence of college residence halls on students. Higher education: Handbook of theory research in Higher Education, 9, 248-307.

Bradford, A. (2017). Deductive Reasoning vs. Inductive Reasoning [Online]. Live Science. Retrieved July 13, 
2019, from https://www.livescience.com/21569-deduction-vs-induction.html

Casuso-Holgado, M. J., Cuesta-Vargas, A. I., Moreno-Morales, N., Labajos-Manzanares, M. T., Barón-López, F. J., \& Vega-Cuesta, M. (2013). The association between academic engagement and achievement in health sciences students. BMC Medical Education, 13(1), 33. https://doi.org/10.1186/1472-6920-13-33

Choi, N. (2005). Self-efficacy and self-concept as predictors of college students' academic performance. Psychology in the Schools, 42(2), 197-205. https://doi.org/10.1002/pits.20048

Foster, K. C. (2008). The Transformative Potential of Teacher Care as Described by Students in a Higher Education Access Initiative. Education and Urban Society, 41(1), 104-126. https://doi.org/10.1177/0013124508321591

Fraenkel, J. R., \& Wallen, N. E. (2003). Observation and interviewing. How to design and evaluate research in education, 5, 455-463.

Goodenow, C. (1993). Classroom belonging among early adolescent students: Relationships to motivation and achievement. The Journal of Early Adolescence, 13(1), 21-43. https://doi.org/10.1177/0272431693013001002

Greene, T. G., Marti, C. N., \& McClenney, K. (2008). The effort-outcome gap: Differences for African American and Hispanic community college students in student engagement and academic achievement. The Journal of Higher Education, 79(5), 513-539. https://doi.org/10.1080/00221546.2008.11772115

Gunuc, S. (2014). The relationships between student engagement and their academic achievement. International Journal on New Trends in Education and Their Implications, 5(4), 216-231.

Gunuc, S., \& Kuzu, A. (2015). Student engagement scale: Development, reliability and validity. Assessment \& Evaluation in Higher Education, 40(4), 587-610. https://doi.org/10.1080/02602938.2014.938019

Handelsman, M. M., Briggs, W. L., Sullivan, N., \& Towler, A. (2005). A measure of college student course engagement. The Journal of Educational Research, 98(3), 184-192. https://doi.org/10.3200/JOER.98.3.184-192

Hausmann, L. R., Schofield, J. W., \& Woods, R. L. (2007). Sense of belonging as a predictor of intentions to persist among African American and White first-year college students. Research in higher education, 48(7), 803-839. https://doi.org/10.1007/s11162-007-9052-9

$\mathrm{Hu}, \mathrm{S} .$, \& Kuh, G. D. (2002). Being (Dis)Engaged in Educationally Purposeful Activities: The Influences of Student and Institutional Characteristics. Research in Higher Education, 43(5), 555-575. https://doi.org/10.1023/A:1020114231387

Johannesson, P., \& Perjons, E. (2014). An introduction to design science. Springer.

Kahu, E. R. (2013). Framing student engagement in higher education. Studies in Higher Education, 38(5), 758-773. https://doi.org/10.1080/03075079.2011.598505

Kember, D., Lee, K., \& Li, N. (2001). Cultivating a sense of belonging in part-time students. International Journal of Lifelong Education, 20(4), 326-341. https://doi.org/10.1080/02601370117754

Krause, K. L., \& Coates, H. (2008). Students' engagement in first-year university. Assessment Evaluation in Higher Education, 33(5), 493-505. https://doi.org/10.1080/02602930701698892

Krejcie, R. V., \& Morgan, D. W. (1970). Determining Sample Size for Research Activities. Educational and Psychological Measurement, 30, 607-610.

Kuh, G. D. (2001a). Assessing What Really Matters to Student Learning Inside The National Survey of Student Engagement. Change: The Magazine of Higher Learning, 33(3), 10-17. https://doi.org/10.1080/00091380109601795

Kuh, G. D. (2001b). The National Survey of Student Engagement: Conceptual framework and overview of psychometric properties. Bloomington, IN: Indiana University Center for Postsecondary Research, 126. https://doi.org/10.1002/ir.283

Kuh, G. D., Kinzie, J. L., Buckley, J. A., Bridges, B. K., \& Hayek, J. C. (2006). What matters to student success: A review of the literature. National Postsecondary Education Cooperative Washington, DC.

Li, Y., Lerner, J. V., \& Lerner, R. M. (2010). Personal and ecological assets and academic competence in early adolescence: The mediating role of school engagement. Journal of youth adolescence, 39(7), 801-815. https://doi.org/10.1007/s10964-010-9535-4 
Moss, P. A. (1994). Can there be validity without reliability? Educational Researcher, 23(2), 5-12.

Nauffal, D. I. (2012). Assessment of student engagement: An analysis of trends. Tertiary Education Management Learning, 18(2), 171-191. https://doi.org/10.1080/13583883.2012.656696

Park, S.-Y. (2005). Student engagement and classroom variables in improving mathematics achievement. Asia Pacific Education Review, 6(1), 87-97. https://doi.org/10.1007/BF03024970

Patrick, H., Ryan, A. M., \& Kaplan, A. (2007). Early adolescents' perceptions of the classroom social environment, motivational beliefs, and engagement. Journal of educational psychology, 99(1), 83. https://doi.org/10.1037/0022-0663.99.1.83

Pike, G. R., \& Kuh, G. D. (2005). First-and second-generation college students: A comparison of their engagement and intellectual development. The Journal of Higher Education, 76(3), 276-300. https://doi.org/10.1080/00221546.2005.11772283

Pineda-Báez, C., José-Javier, B.-A., Rubiano-Bello, Á., Pava-García, N., Suárez-García, R., \& Cruz-Becerra, F. (2014). Student engagement and academic performance in the Colombian University context. RELIEVE-Revista Electrónica de Investigación y Evaluación Educativa, 20(2). https://doi.org/10.7203/relieve.20.2.4238

Research Methodology. (2019). Research Methodology [Online]. www.research-methodology.net. Retrieved July 11, 2019, from https://research-methodology.net/research-methodology/research-approach/

Saunders, M., Lewis, P., \& Thornhill, A. (2009). Research Methods for Business Students. Prentice Hall.

Schumacher, S., \& Mcmillan, J. J. B. P. E. (2006). Research in Education Evidence-Based Inquiry.

Sekaran, U., \& Bougie, R. (2010). Research Methods For Business: A Skill Building Approach. Chichester, West Sussex, United Kingdom, John Wiley \& Sons Ltd.

Sheard, J., Carbone, A., \& Hurst, A. J. (2010). Student engagement in first year of an ICT degree: Staff and student perceptions. Computer Science Education, 20(1), 1-16. https://doi.org/10.1080/08993400903484396

Terenzini, P. T., Pascarella, E. T., \& Blimling, G. S. (1996). Students' out-of-class experiences and their influence on learning and cognitive development: A literature review. Journal of college student development.

Wang, Y., Tian, L., \& Huebner, E. S. (2019). Basic psychological needs satisfaction at school, behavioral school engagement, and academic achievement: Longitudinal reciprocal relations among elementary school $\begin{array}{lllll}\text { students. } & \text { Contemporary } & \text { Educational } & \text { Psychology, } & \text { 56, }\end{array}$ https://doi.org/10.1016/j.cedpsych.2019.01.003

Wara, E., Aloka, P. J., \& Odongo, B. C. (2018). Relationship between Cognitive Engagement and Academic Achievement among Kenyan Secondary School Students. Mediterranean Journal of Social Sciences, 9(2), 61-72. https://doi.org/10.2478/mjss-2018-0026

Willms, J. D. (2003). Student engagement at school: A sense of belonging and participation. .

Yong, A. G., \& Pearce, S. (2013). A beginner's guide to factor analysis: Focusing on exploratory factor analysis. Tutorials in quantitative methods for psychology, 9(2), 79-94. https://doi.org/10.20982/tqmp.09.2.p079

York, T. T., Gibson, C., Rankin, S., \& Evaluation. (2015). Defining and Measuring Academic Success. Practical Assessment, Research Evaluation, 20.

\section{Copyrights}

Copyright for this article is retained by the author(s), with first publication rights granted to the journal.

This is an open-access article distributed under the terms and conditions of the Creative Commons Attribution license (http://creativecommons.org/licenses/by/4.0/). 